\title{
DISTRIBUTION OF RADIATION DAMAGE IN GRAPHITE
}

By

R. E. Nightingale and W. A. Snyder

Materials Development

Reactor and Fuels Research and Development Operation

June 18, 1957

\section{HANFORD ATOMIC PRODUCTS OPERATION RICHLAND, WASHINGTON}

\begin{abstract}
Work performed under Contract No. W-31-109-Eng-52 between
\end{abstract} the Atomic Energy Commission and General Electric Company

Printed by/for the U. S. Atomic Energy Commission

Printed in USA. Price 20 cents. Available from the Office of Technical Services U. S. Department of Commerce Washington 25, D. C. 


\section{DISCLAIMER}

This report was prepared as an account of work sponsored by an agency of the United States Government. Neither the United States Government nor any agency Thereof, nor any of their employees, makes any warranty, express or implied, or assumes any legal liability or responsibility for the accuracy, completeness, or usefulness of any information, apparatus, product, or process disclosed, or represents that its use would not infringe privately owned rights. Reference herein to any specific commercial product, process, or service by trade name, trademark, manufacturer, or otherwise does not necessarily constitute or imply its endorsement, recommendation, or favoring by the United States Government or any agency thereof. The views and opinions of authors expressed herein do not necessarily state or reflect those of the United States Government or any agency thereof. 


\section{DISCLAIMER}

Portions of this document may be illegible in electronic image products. Images are produced from the best available original document. 

(TID-4500, 19th Ed.)

INTERNAL DISTRIBUTION

Copy Number

$\begin{aligned} 1 & \text { L. P. Bupp } \\ 2 & \text { J. L. Carter, Jr. } \\ 3 & \text { D. H. Curtiss } \\ 4 & \text { J. E. Faulkner } \\ 5 & \text { R. E. Nightingale } \\ 6 & \text { W. A. Snyder } \\ 7 & \text { F. W. Woodfield } \\ 8-10 & \text { Extra } \\ 11 & \text { 300. Files } \\ 12 & \text { Record Center }\end{aligned}$

\section{EXTERNAL DISTRIBUTION}

\section{Copy Number}

$13-15$

16

$17-26$

27

$28-32$

33

34

35

$36-38$

$39-40$

$41-42$

$43-46$

$48-51$

52

53

54

55

56

$57-58$

59

$60-62$

63

64

65

$66-67$

68
Aberdeen Proving Ground

Alco Products, Inc.

Argonne National Laboratory

Armed Forces Special Weapon Project, Washington

Armed Services Technical Information Agency, Dayton Army Medical Research Laboratory

Atlantic Fleet

Atomic Energy Commission, Patent Branch

Atomic Energy Commission, Technical Library

Atomics International

Battelle Memorial Institute

Bettis Plant

Boeing Airplane Company

Brookhaven National Laboratory

Brush Beryllium Company

Bureau of Medicine and Surgery

Bureau of Ships. (Code 590)

Carnegie Institute of Technology

Chicago Patent Group

Consolidated Vultee Aircraft Corporation

Convair-General Dynamics

Defense Research Member.

Department of Army, Office of Quartermaster General

Department of Food Technology (MIT)

Department of Naval (Code 422)

Department of the Army, G-2

Division of Raw Materials, Denver 
EXTERNAL DISTRIBUTION (contd.)

Copy Number

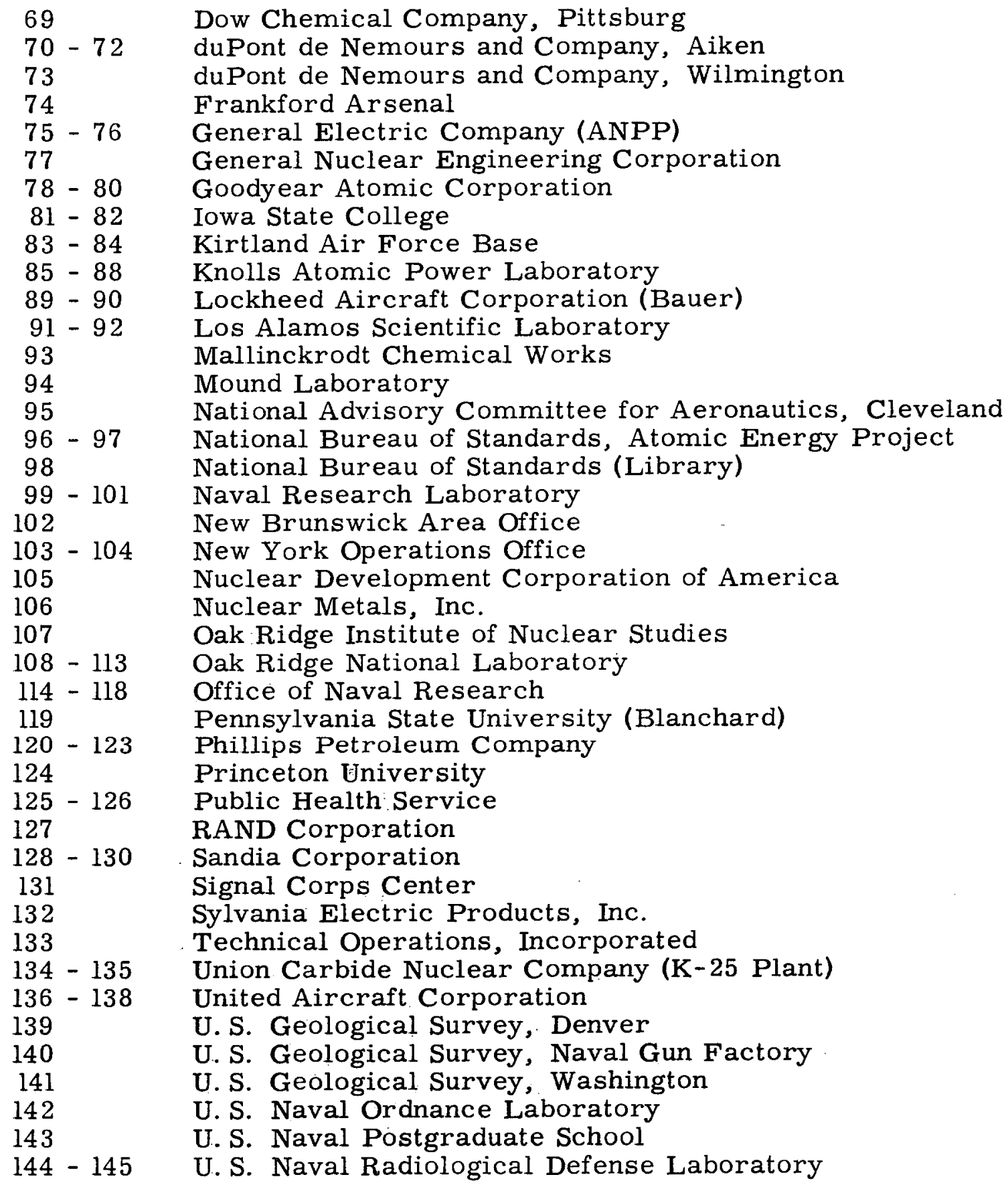


EXTERNAL DISTRIBUTION (contd.)

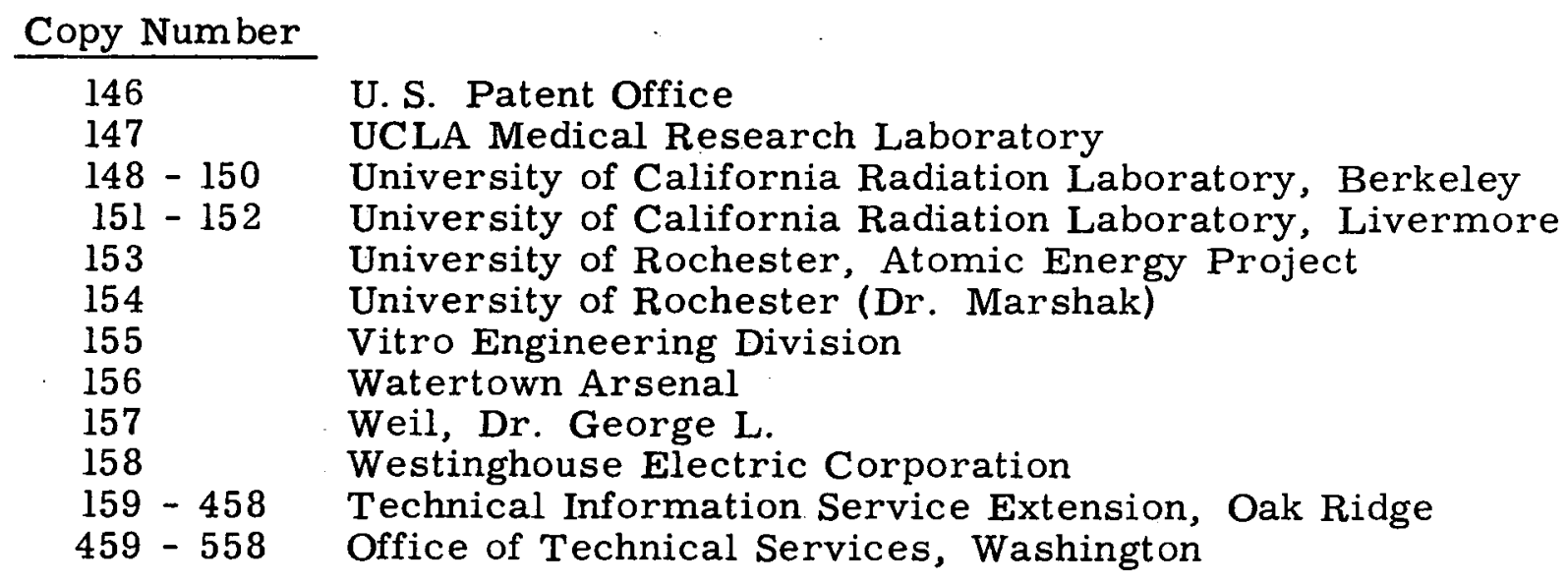




\section{DISTRIBUTION OF RADIATION DAMAGE IN GRAPHITE}

\section{INTRODUCTION}

The radiation damage effects occurring in graphite have been thoroughly studied. ${ }^{(1,2)}$ As a result of interstitials, vacancies and other defects created by fast energetic neutrons and carbon atoms, the distance between layer planes increases. Electrical and thermal conductivity are greatly reduced, the crystallites are strained and disordered and large dimensional changes result. Graphite is gradually changed from a soft, lubricating, to a hard abrasive material.

Some of these effects are of practical importance in the design and operation of graphite moderated reactors. Dimensional changes resulting from radiation damage are of particular interest. The total dimensional change as a function of neutron exposure is known for a number of different types of graphite. Much less well known is the manner in which the damage effects are distributed, say, as measured by the ease with which they may be annealed. This suggest another method of studying the mechanism by which property changes occur. Damage distribution may be specified in several ways. Through thermal annealing experiments the amount of property annealed at a given temperature may be determined. It is also possible to estimate the activation energy for a given temperature-time annealing history and this may be used to characterize the damage annealed.

In this report the distribution of damage of several properties is presented. Annealing experiments of the type to be described are not suited for a detailed study of any part of the damage release curve. Instead, the purpose of these experiments was to determine, over a wide range of

(1) W. K. Woods, L. P. Bupp, and J. F. Fletcher, Proceedings of the International Conference on Peaceful Uses of the Atom, Paper 746 (1955).

(2) G. R. Hennig and J. E. Hove, ibid, Paper 751 (1955). 
activation energy (or annealing temperature), the gross annealing characteristics of several properties. An effort has been made to relate changes in length of graphite samples with changes in $\mathrm{C}_{0}$, the distance between alternate layer planes, and $\mathrm{L}_{\mathrm{c}}$, the crystallite size along the $\mathrm{C}_{\mathrm{O}}$ axis. These and other studies are part of an effort to answer the question: How does reactor radiation cause dimensional changes in graphite?

\section{SUMMARY AND CONCLUSIONS}

A series of graphite samples with $30 \mathrm{C}$ reactor irradiation exposure ranging from $400-5700 \mathrm{MD} / \mathrm{T}$ was thermally annealed. Changes in length, 1 , interlayer spacing, $\mathrm{C}_{\mathrm{O}}$, and crystallite size, $\mathrm{L}_{\mathrm{C}}$, were observed. Annealing was performed with temperature increases in $50 \mathrm{C}-150 \mathrm{C}$ intervals and an approximate activation energy, $\mathbf{E}$, was calculated for each time-temperature annealing schedule. Changes in properties with activation energy were compared through the exposure range.

$\mathrm{C}_{\mathrm{O}}$ changed almost linearly with $\mathrm{E}$ up to about $100 \mathrm{kcal}$. All but the highest exposure sample $(5700 \mathrm{MD} / \mathrm{T})$ were almost back to their virgin values at $\mathrm{E}=140 \mathrm{kcal} / \mathrm{g}$-atom. A larger fraction of the $\mathrm{C}_{\mathrm{O}}$ damage accumulated in the higher activation energies as the sample exposure was increased. This probably resulted from an accumulation of larger polyatomic carbon species between the layer planes.

$\mathrm{L}_{\mathrm{c}}$ annealing began first in the less damaged samples. It was essentially complete at $\mathrm{E}=130$ for the $400 \mathrm{MD} / \mathrm{T}$ sample but had only begun in the $5700 \mathrm{MD} / \mathrm{T}$ sample. Like $\mathrm{C}_{\mathrm{O}}$ damage, a greater fraction of $\mathrm{L}_{\mathrm{c}}$ damage was found in the higher activation energies in the more highly damaged samples.

Length and $\mathrm{C}_{\mathrm{o}}$ annealing were somewhat similar. Both were approximately linear in the low activation energy region. In all but the 5700 MD/T sample, length annealing was completed at about $145 \mathrm{kcal} / \mathrm{g}$-atom. Thermal annealing of $\mathrm{C}_{\mathrm{O}}$ damage allowed the crystallite to contract about 6 times faster than the length. It is likely that the crystallites contracted into void volumes so that only a fraction of the $\mathrm{C}_{\mathrm{O}}$ contraction resulted in length contraction.

UNCLASSIFIED 


\section{EXPERIMENTAL}

A series of seven CSF* graphite samples having a wide range of exposures (400 - $5700 \mathrm{MD} / \mathrm{T}^{*}$ ) was chosen for the annealing experiments. Each sample was approximately four inches long by 0.426 inches in diameter. They were cut perpendicular to the long axis of a 4 inch $\mathrm{x} 4$ inch $\mathrm{x} 4$ foot bar. The cooled test-hole facilities in the Hanford reactors were used to irradiate the samples. Temperature during irradiation of these samples was $20 \mathrm{C} \pm$ $10 \mathrm{C}$. The uncertainty in the neutron exposures was approximately \pm 15 per cent.

Graphite Annealing

Physical properties were measured prior to and following irradiation. Annealing of all samples in the series was carried out simultaneously and was begun at $90 \mathrm{C}$. Property measurements were repeated and the samples annealed at a higher temperature. Up to $250 \mathrm{C}$ annealing was done in a conventional laboratory oven for periods of approximately one day. Above $250 \mathrm{C}, 6-7$ hour anneals were carried out in a graphite tube furnace. This consisted of a graphite resistance tube 4 feet long by 2-3/4 inches $O$. D. by 2 inches I. D. The furnace was heated electrically by passing current through the tube between large graphite electrodes 27 inches apart. It was insulated with thermax, fire brick and asbestos. The samples were placed inside graphite carriers containing four samples each and positioned at the center of the furnace. Temperatures were controlled and measured with chromel-alumel thermocouples in the range $300 \mathrm{C}$ to $900 \mathrm{C}$, with $\mathrm{Pt}$, $\mathrm{Pt}-\mathrm{Rh}$ thermocouples in the range $1000 \mathrm{C}-1300 \mathrm{C}$, and with an optical pyrometer above $1300 \mathrm{C}$. Temperature variation in these ranges was $\pm 3 \mathrm{C}$, $\pm 4 \mathrm{C}$, and $\pm 20 \mathrm{C}$ respectively. A slow stream of argon or nitrogen was passed through the furnace to prevent oxidation.

* CSF graphite is manufactured from Cleves coke and standard pitch and is purified by the F process.

* The unit of exposure, megawatt-days per ton, $M D / T$, is the amount of neutron irradiation received by the sample during the time required to generate one megawatt-day of fission energy in a ton of uranium nearest the sample.

UNCLASSIFIED 
The annealing schedule was determined from the amount of property change expected for a given time and temperature. A convenient time of approximately 7 hours was used in the tube furnace. This allowed a sufficiently long isothermal anneal to make very small, when compared with the total annealing done, that amount of annealing occurring while the temperature was increasing to the desired value and decreasing back to room temperature. With the annealing time thus established, the annealing temperature was chosen to give an amount of property change that could be accurately measured. At the same time the amount of annealing accomplished during a single run was kept to a minimum in order to better define the distribution of damage in the sample.

\section{RESULTS AND DISCUSSION}

Figure 1 shows the annealing results on $\mathrm{C}_{\mathrm{O}}$. $\mathrm{X}$-ray measurements were made with a Norelco 180 degree $\mathrm{x}$-ray diffractometer using $\mathrm{Cu} \mathrm{K} \alpha$ x-rays and Ni-Co monochromatizing Ross filters. $\mathrm{C}_{0}$ values were calculated from the 002 reflection taken from the end of the samples. In order to improve the precision of these measurements, the samples were removed from the holder, remounted, and the 002 peak position re-determined. This was repreated several times and average values and the standard deviation from the average were calculated. These are represented on the annealing curve (Figure 1) by vertical lines of appropriate length. The uncertainty in $\mathrm{C}_{\mathrm{O}}$ is greater for the highly damaged samples where considerable line broadening has occurred.

The per cent property change has been plotted as a function of approximate activation energy. The activation energy used was calculated by $\mathbf{E}=\mathrm{RT} \ln \mathbf{C t}$

where

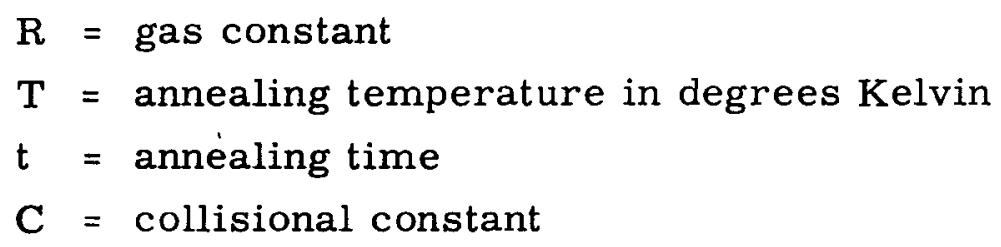


Vand ${ }^{(3)}$ introduced the concept of a large number of kinetic processes distributed in activation energy and found that for certain simplifications, the activation energy was given by the above equation. Primak ${ }^{(4)}$ has discussed the kinetics of processes distributed in activation energy and generalized the Vand treatment. These ideas have been applied to the thermal annealing kinetics of irradiated graphite ${ }^{(5)}$ for which a value for the collisional constant, $\mathrm{C}=7.5 \times 10^{13} \mathrm{sec}^{-1}$, was found to be satisfactory.

Physical property change vs activation energy was preferable in this work to make more comparable annealing runs in which annealing times were different. Accurate activation energies are not claimed since reaction order, the relation between number of defects annealed and resulting property change, true collisional constants, and other factors have not been thoroughly evaluated.

In Figure 1 it is seen that the per cent decrease in $\mathrm{C}_{0}$ is almost linear with exposure at the lower activation energies. A more detailed study of the kinetics of $\mathrm{C}_{\mathrm{O}}$ annealing ${ }^{(5)}$ shows that for samples with $550 \mathrm{MD} / \mathrm{T}$ exposure, a rather large decrease in $\mathrm{C}_{\mathrm{O}}$ occurs at about $33 \mathrm{kcal} / \mathrm{g}$-atom*. The sensitivity of this method is insufficient to show that here. Significant

(3). V. Vand, Proc. Roy Soc (London), 55, 222 (1943).

(4), W. Primak, Phy Rev, 100, 1677 (1955).

(5) R. E. Nightingale, Thermal Annealing Kinetics of Interlayer Spacing Damage in Irradiated Graphite, HW-37406, June 21, 1955.

* Several properties show a pronounced peak in the damage release curves at $\sim 33 \mathrm{kcal}$ and this has often been referred to in the graphite literature as the " $200^{\circ} \mathrm{C}$ peak" because, for convenient annealing periods, it anneals at about this temperature. This region has been studied in most detail and it is found that the peak becomes broader and much less pronounced in samples above $600 \mathrm{MD} / \mathrm{T}$ exposure. 
departures from a linear curve occur, but it is not yet possible to associate these with specific annealing processes. It should also be noted that not only is $\mathrm{C}_{\mathrm{o}}$ damage greater for samples with greater neutron exposure, but also the damage accumulates at higher activation energies. For the highest exposure $(5700 \mathrm{MD} / \mathrm{T})$ an activation energy of $100 \mathrm{kcal} / \mathrm{g}$-atom is necessary to anneal one-half of the $\mathrm{C}_{\mathrm{O}}$ damage, while, for the $400 \mathrm{MD} / \mathrm{T}$ exposure only $65 \mathrm{kcal} / \mathrm{g}$-atom is required.

$\mathrm{C}_{\mathrm{o}}$ expansion results largely from interstitial carbon atoms trapped between the layer planes. Because the planes are bound by weak van der Waal forces, they may be forced apart quite easily to accommodate the interstitial atoms. Single interstitial carbon atoms would be quite mobile since no strong chemical bonds would likely be formed with the layer plane carbon atoms. As a result, in lightly damaged samples, $\mathrm{C}_{\mathrm{O}}$ damage is quite easily annealed. As damage accumulates, the probability increases that two carbon atoms will combine to form larger, less mobile $\mathrm{C}_{2}$ molecules requiring greater activation energy for annealing. This mechanism by which less mobile groups of carbon atoms are formed, combined with a large number of different environments presented by vacancies or multi-vacancies in the carbon layer planes probably accounts for the distribution of activation energies which complicates the annealing process.

The effect of annealing on the average crystallite size along the $\mathrm{C}_{\mathrm{o}}$ axis, $\mathrm{L}_{\mathrm{c}}$, was estimated from the integral breadths of the 002 reflection using the method of Jones. ${ }^{(6)}$ The results are shown in Figure 2. In the early annealing runs, $L_{c}$ was calculated from the 002 peaks of the sample ends. Because of the $x$-ray penetration effect and the ability to get better precision, it was decided to change to thin powders for this measurement. After the $600 \mathrm{C}(\mathrm{E}=75 \mathrm{kcal})$ anneal this was done with much more reproducible $L_{c}$ values. The average deviation of the data points from the curves was about $30 \AA$

(6) F. W. Jones, Proc Roy Soc., 166A, 16 (1938). 
Very little annealing to $\mathrm{L}_{c}$ was accomplished at activation energies less than $50 \mathrm{kcal}$. For the samples with up to $1200 \mathrm{MD} / \mathrm{T}$ exposure a considerable amount of annealing was done in the region $E=50-100$, while little annealing occurred until $\mathrm{E}>100$ for the more highly damaged samples. $\mathrm{L}_{\mathrm{c}}$ did not start to anneal in the $5700 \mathrm{MD} / \mathrm{T}$ sample until $\mathrm{E}>130$ were reached $(\sim 1300 \mathrm{C})$. Again, a greater fraction of the radiation damage is distributed in the higher activation energies in the more highly damaged samples.

For samples exposed at $30 \mathrm{C}$ to less than about $800 \mathrm{MD} / \mathrm{T}\left(\mathrm{C}_{\mathrm{O}}\right.$ less than $7.1 \AA$ ) the lattice strains resulting from vacancies, interstitial atoms and other more complex defects probably account for most of the 002 peak broadening. However, as crystal damage accumulates broadening resulting from a decrease in crystallite size becomes more important and after about $1000 \mathrm{MD} / \mathrm{T}$ the broadening becomes much more rapid. Because of the similarity between peak shapes and positions of the 002 reflections from highly irradiated graphite and carbon or lamp blacks, the line broadening for samples exposed to $1700 \mathrm{MD} / \mathrm{T}$ and greater $\left(\mathrm{C}_{\mathrm{o}}\right.$ greater than $7.4 \AA$ ) has been ascribed principally to the decrease in crystallite size. In very highly damaged samples only a skeleton of the crystallite may finally be left and very high activation energies will be required to repair the damage.

Length changes vs activation energy are shown in Figure 3. Measurements were made with a micrometer at room temperature and are accurate to \pm .0002 inch. In general annealing begins immediately at the lowest activation energy. An exception to this is the $5700 \mathrm{MD} / \mathrm{T}$ sample where a small but significant amount of expansion occurs before contraction begins. Length annealing does not closely follow the $L_{c}$ annealing, particularly in the highly damaged samples. For example, a considerable amount of length annealing was accomplished at $130 \mathrm{kcal} / \mathrm{g}$-atom in the $5700 \mathrm{MD} / \mathrm{T}$

(7) J. R. Townsend and C. A. Lund, X-ray Diffraction Peak Shapes from Irradiated Graphites, HW-25019, May 12, 1952. 
sample, while practically no $L_{c}$ annealing was done. $C_{o}$ and length annealing are somewhat more similar in their annealing behavior, the per cent change in $\mathrm{C}_{0}$ being some 6 times as great as the per cent length change.

Length changes in graphite from radiation damage are not easy to understand. Perhaps the most satisfactory explanation for samples exposed around room temperature relates $\mathrm{C}_{\mathrm{o}}$ and length changes. Thermal annealing of $\mathbf{C}_{0}$ expansion allows the crystallite to contract about 6 times faster than the length contraction. Many of the crystallites contract leaving voids or amorphous carbon volumes so that only a fraction of the $\mathrm{C}_{\mathrm{o}}$ contraction results in length contraction. While this mechanism of length changes has probably been vastly oversimplified, it does account for the gross features. When graphite is exposed at higher temperatures a different mechanism must exist since no such simple relationship between $\mathbf{C}_{\mathrm{o}}$ and length changes is found. 


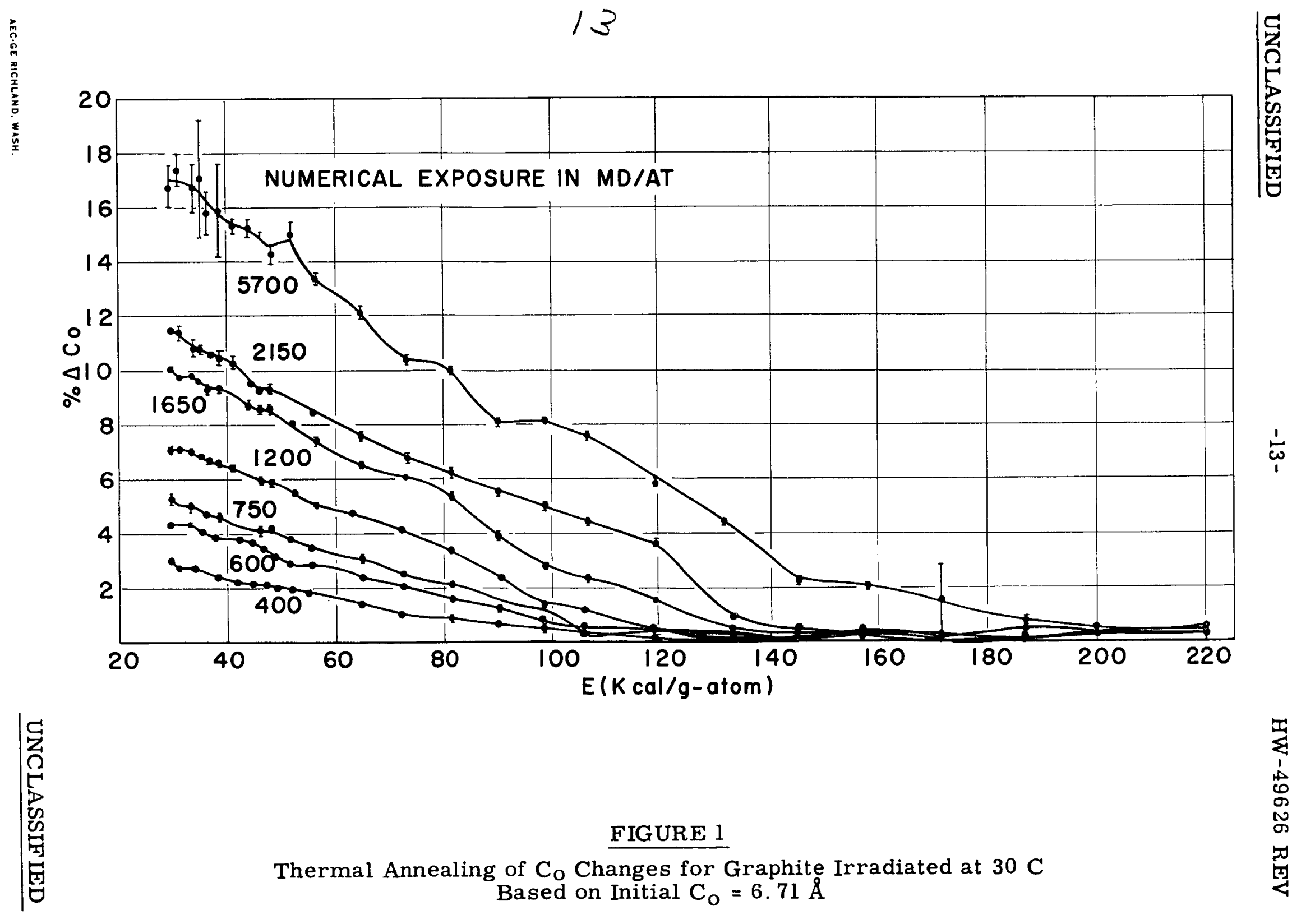




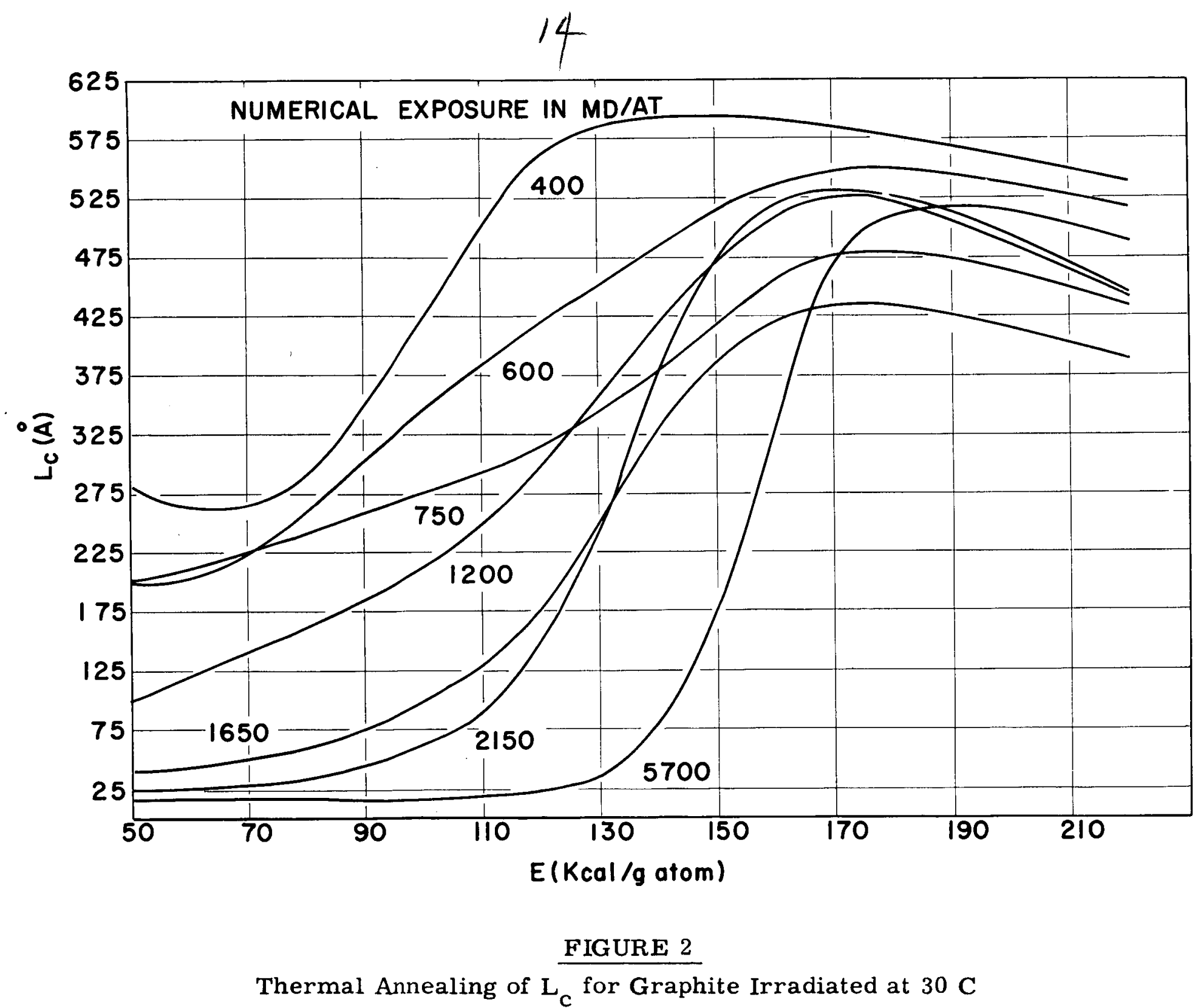




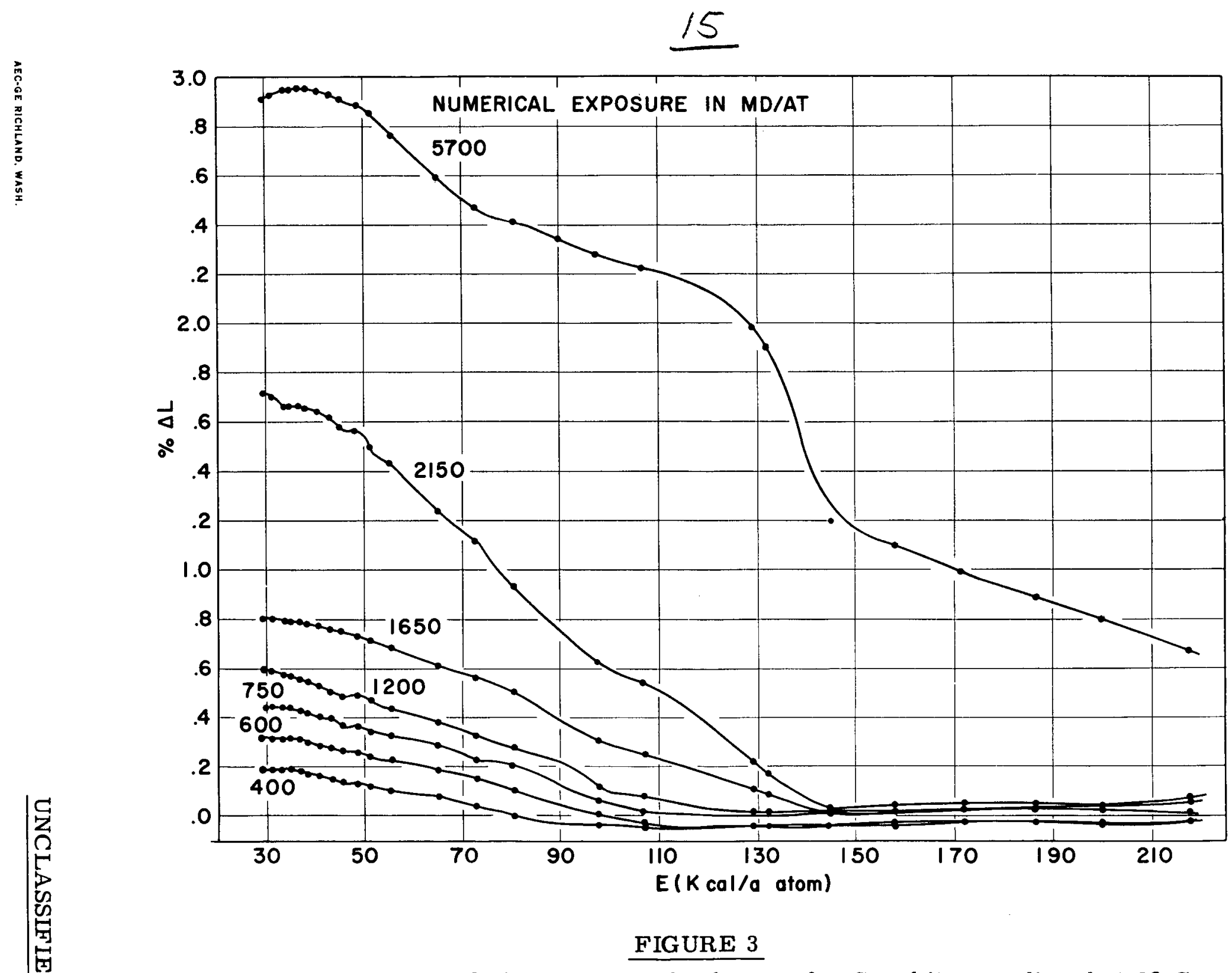

Thermal Annealing of Physical Length Changes for Graphite Irradiated at $30 \mathrm{C}$ 